\title{
INVESTIGATION OF KONDAGOGU GUM TO DEVELOP TRANSDERMAL FILM OF REPAGLINIDE
}

\section{POREDDY SRIKANTH REDDY ${ }^{*}$, PENJURI SUBHASH CHANDRA BOSE ${ }^{1}$, VUPPULA SRUTHI ${ }^{1}$, DAMINENI SARITHA $^{2}$}

${ }^{1}$ Department of Pharmaceutics, MNR College of Pharmacy, Sangareddy, Telangana, India. ${ }^{2}$ Department of Pharmaceutics, Sultan-ul-Uloom College of Pharmacy, Hyderabad, Telangana, India. Email: srikanthreddyporeddy@gmail.com

Received: 22 January 2018, Revised and Accepted: 10 March 2018

ABSTRACT

Objective: In the present study, an attempt was made to develop polymeric blend transdermal patch of repaglinide using hydroxypropyl methyl cellulose (HPMC) K4M and kondagogu gum.

Methods: A series of repaglinide drug-incorporated HPMC K4M-kondagogu gum matrix films were prepared by solvent casting method. The prepared transdermal films were evaluated for various parameters such as thickness, tensile strength, folding endurance, \% elongation, \% moisture content, \% moisture uptake, \% drug content, in vitro drug release, and drug excipient compatibility.

Results: The Fourier-transform infrared spectra of the pure drug as well as drug-incorporated formulation indicated that no chemical interaction occurred between the drug and the polymers used. Differential scanning calorimetry thermograms of the pure drug and prepared formulation indicated that the drug has dispersed in micron level in the prepared films. In vitro release study data of prepared formulations were fitted into various mathematical models, and the best-fit model was found to be Higuchi model.

Conclusion: Among all the formulations studied, the formulation F4 was found to be an optimized composition for efficient transdermal delivery of repaglinide for $24 \mathrm{~h}$ study period. Stability studies of the drug formulations concluded that the drug was stable in the optimized formulation for the study period.

Keywords: Hydroxypropyl methyl cellulose K4M, Kondagogu gum, Transdermal film, Repaglinide.

(C) 2018 The Authors. Published by Innovare Academic Sciences Pvt Ltd. This is an open access article under the CC BY license (http://creativecommons. org/licenses/by/4. 0/) DOI: http://dx.doi.org/10.22159/ajpcr.2018.v11i4.24873

\section{INTRODUCTION}

Natural polymers and their derivatives are used extensively to prepare various pharmaceutical dosage forms and novel drug delivery systems and thus can compete with synthetic polymeric materials which are widely utilized in the present market [1]. Natural polysaccharides hold several distinct advantages compared to synthetic polymeric materials as they are non-toxic, biodegradable, less expensive, and easily available.

Over the past few decades, natural biodegradable polysaccharides such as guar gum, chitosan, carrageenans, sodium alginate (Na-alginate), pectin, xanthan gum, gellan gum, and agar have been widely used [2,3]. These polymers can be used in various ways in the formulation of targeted and controlled drug delivery systems as they have different derivatizable groups, a wide range of molecular weight, and varying chemical composition. Transdermal drug delivery system has been showing an increased interest in the drug administration through the skin for both local therapeutic effects as well as for systemic delivery of drugs. Development of transdermal delivery system started in 1970s, and in 1979, the first transdermal patch of scopolamine was approved by the United States FDA for the treatment of motion sickness, and later, a nitroglycerine patch was marketed for the treatment of angina pectoris $[4,5]$

Fundamentally, thin films are good candidates for targeting sensitive site which may not be possible using tablets or liquid formulations. Transdermal films have shown the capabilities to improve the onset of drug action, reduce the dose frequency, and enhance the drug efficacy [6-9]. Similarly, transdermal films are useful for eliminating side effects of a particular drug and reducing extensive metabolism which is caused by proteolytic enzymes. Ideal films exhibit desirable features such as sufficient drug loading capacity, fast dissolution rate or long residence time at the site of administration, and acceptable formulation stability. They should also be non-toxic, biocompatible, and biodegradable $[10,11]$.

Kondagugu gum (KG) is the dried exudate obtained from the tree Cochlospermum gossypium belonging to the family Bixaceae [12]. It is a high molecular weight complex acetylated polysaccharide consisting mainly of D-galacturonic acid, D-galactose, and L-rhamnose [13]. KG has demonstrated a lot of interest in the preparation of hydrophilic matrix tablets because of its properties such as high water swellability, nontoxicity, and low cost. Unlike other water-soluble gums, it does not dissolve in water but absorbs to form a viscous colloidal solution [14]. Powdered KG swells in cold water to an extent that a 3-4\% sol will produce a gel of uniform smoothness and texture.

Kondagogu gum has also been used for biosorption of toxic heavy metals such as nickel and total chromium from aqueous solutions [15]. Gum kondagogu modified magnetic nano adsorbent has also been prepared for removing toxic metal ions from industrial effluents [16]. It was used as a carrier in preparing floating drug delivery system [17] and as a polyelectrolyte complex in combination with chitosan [18]. Even though KG is an important forest product, its commercial exploitation has been limited. Hydroxypropyl methyl cellulose (HPMC) K4M is a water-soluble cellulose derivative designed to perform many functions in pharmacy. It has a viscosity range of 2,700-5,040 cps and widely used in the formulation of films.

Diabetes mellitus is a major and growing health problem worldwide which is an important cause of prolonged ill-health and early death. It is a chronic metabolic disorder characterized by a high blood glucose concentration (hyperglycemia) caused by insulin deficiency, and it is often combined with insulin resistance [19]. Repaglinide is an oral blood glucose-lowering drug of the meglitinide class and used to treat non-insulin-dependent diabetes mellitus. It lowers blood glucose level by stimulating the release 
of insulin from the pancreas. It has an extremely short half-life of $1 \mathrm{~h}$. In addition, the oral bioavailability of repaglinide is low (56\%) due to extensive hepatic first-pass metabolism. Dosage frequency of repaglinide is $0.5-4 \mathrm{mg}$ and for $3-4$ times in a day. It has melting point of $130-131^{\circ} \mathrm{C}$ and molecular weight 452.58 . Topical preparation of repaglinide may be beneficial to the patient since it reduces adverse effects and avoids the hepatic first-pass metabolism [20-22].

In the present study, an attempt was made to develop polymeric blend transdermal patch of repaglinide using HPMC K4M and kondagogu gum. Different formulations were prepared by varying the concentration of gums, and the prepared films were evaluated.

\section{MATERIALS AND METHODS}

Materials

Repaglinide was received as gift sample from Lupin Limited, Goa, India. Kondagogu gum was purchased from Girijan Cooperative Society, Government of Andhra Pradesh, Hyderabad, India. HPMCK4M, polyethylene glycol 400, and propylene glycol were purchased from Sigma Aldrich, Mumbai, India. All other chemicals used were of analytical grade and purchased from Loba Chemie, Mumbai, India.

\section{Purification of gum [14]}

First, the foreign extraneous matter such as bark was physically separated from kondagogu gum, then powdered using mixer grinder, and passed through sieve \#80. The powdered gum was dispersed in distilled water using a magnetic stirrer to get a $1 \%$ solution, which is kept in sonicator for $10 \mathrm{~min}$ until it was clear and then added to equimolar mixture of acetone and ethanol $(2: 1 \mathrm{v} / \mathrm{v})$ to get precipitation of gum. Precipitated polymer was kept in an oven at $40^{\circ} \mathrm{C}$ for drying, powdered, and then used for further studies.

\section{Preparation of transdermal patch [23]}

Matrix-type transdermal patches of repaglinide were prepared using solvent casting method (Table 1). Required quantity of polymers, HPMC K4M, and kondagogu gum was accurately weighed and dispersed in water using a magnetic stirrer. The required quantity of drug was dissolved in $5 \mathrm{~mL}$ of methanol and added to the polymer solution. To the above mixture, polyethylene glycol $400(20 \% \mathrm{w} / \mathrm{w}$ of total polymer) as plasticizer and propylene glycol $(15 \% \mathrm{w} / \mathrm{w}$ of total polymer) as permeation enhancer were added. The resulted uniform solution was cast on the Petri dish and dried at room temperature for $24 \mathrm{~h}$. The dried films were cut into required size, wrapped in aluminum foil, and kept in a desiccator containing a saturated solution of $\mathrm{CaCl}_{2}$ as a desiccant $(29 \% \mathrm{RH})$ at room temperature $\left(32^{\circ} \mathrm{C}\right)$ until use.

\section{Mechanical properties [24]}

Mechanical properties such as tensile strength and percentage elongation at break of the prepared transdermal films were measured as per ASTM D 685 using Universal Testing Machine (Instron 4309). A minimum of three samples were tested for each composition, and the average value was recorded. The thickness of the dry films was measured using microprocessor coating thickness gauze (Quint sonic, Mumbai, India). Thickness of the patch was measured at three different places, and the mean value was calculated. Six films $\left(2.5 \mathrm{~cm}^{2}\right)$ from each batch were randomly selected for weight variation. Films were weighed individually, and then the average weight was measured. The difference between individual and average weight indicated the weight variation.

\section{Folding endurance [25]}

A strip of film of specific surface area $(3 \mathrm{~cm} \times 2 \mathrm{~cm})$ was cut and folded repeatedly at one place till it broke. The number of times the film was folded before breaking at the same place represented folding endurance for the formulation.

\section{Drug content analysis [26]}

For drug content analysis, films of known area $(2.5 \mathrm{~cm} \times 2.5 \mathrm{~cm})$ were taken in $10 \mathrm{~mL}$ of volumetric flask and casting solvent mixture was added to it. The flasks were shaken in a water bath at $37^{\circ} \mathrm{C}$ for $2 \mathrm{~h}$, filtered through Whatman filter paper No. 1, and suitably diluted before drug content measurement using ultraviolet (UV)-visible spectrophotometer (UV-1800, SHIMADZU, Japan) at $241 \mathrm{~nm}$

\section{Moisture content [27]}

The films of repaglinide were weighed individually and kept in a desiccator containing a saturated solution of $\mathrm{CaCl} 2(29 \%$ of relative humidity) at room temperature $\left(32^{\circ} \mathrm{C}\right)$ for $24 \mathrm{~h}$. Subsequently, the films were weighed intermittently until a constant weight was achieved. The percentage of moisture uptake was calculated based on the difference between final and initial weight divided by initial weight.

\section{Moisture uptake [27]}

The weighed films kept in a desiccator for $24 \mathrm{~h}$ at room temperature $\left(32^{\circ} \mathrm{C}\right.$ ) were taken out and exposed to $75 \%$ relative humidity (saturated solution of $\mathrm{NaCl}$ ) until a constant weight was obtained. The percentage of moisture uptake was calculated as the difference between final and initial weight divided by initial weight.

\section{Water vapor permeability (WVP) [28]}

For WVP measurement, glass test tubes of $25 \mathrm{~mL}$ capacity were taken and filled with $20 \mathrm{~mL}$ of distilled water. The weight of each filled test tube was measured $1 \mathrm{~h}$ before closing the openings of glass test tubes by films. The area available for vapor permeation was $2.54 \mathrm{~cm} 2$, and all the containers were maintained at constant room temperature $\left(32^{\circ} \mathrm{C}\right)$ for $24 \mathrm{~h}$. The final weight was calculated after $1 \mathrm{~h}$, and the WVP was calculated using the following equation:

$\mathrm{WVP}=\mathrm{W} / \mathrm{A}$

Where $\mathrm{W}$ is the mean loss in weight $(\mathrm{g})$ of the containers and $\mathrm{A}\left(\mathrm{m}^{2}\right)$ is the area of the exposed surface.

Fourier-transform infrared (FTIR) spectrophotometry $[20,22]$

To evaluate the integrity and compatibility of repaglinide with the carrier polymers and the excipients used in the polymer-drug matrix formulations, IR spectra of the drug and its optimized formulation were obtained by FTIR spectrophotometer (Perkin-Elmer-1000, Japan), using a potassium bromide pellet method.

\section{Differential scanning calorimetry (DSC) [27]}

All dynamic DSC studies were carried out using DuPont thermal analyzer with 2010 DSC Q 200, module. The instrument was calibrated

Table 1: Formulation chart for preparing transdermal films

\begin{tabular}{llllll}
\hline $\begin{array}{l}\text { Formulation } \\
\text { code }\end{array}$ & $\begin{array}{l}\text { Repaglinide } \\
(\mathbf{m g})\end{array}$ & HPMCK4M (mg) & Kondagogu gum (mg) & Polyethylene glycol 400 (\% w/w) & Propylene glycol (\% w/w) \\
\hline F1 & 200 & 1000 & - & 20 & 15 \\
F2 & 200 & 900 & 100 & 20 & 15 \\
F3 & 200 & 800 & 200 & 20 & 15 \\
F4 & 200 & 700 & 400 & 20 & 15 \\
F5 & 200 & 600 & 500 & 20 & 15 \\
F6 & 200 & 500 & & & 15 \\
\hline
\end{tabular}

HPMC: Hydroxypropyl methyl cellulose 
before testing using high purity indium metal as standard and the scans of the samples were recorded in the temperature range $0-300^{\circ} \mathrm{C}$ under nitrogen gas purge at a heating rate of $10^{\circ} \mathrm{C} / \mathrm{min}$.

\section{In vitro release studies [24,27]}

The in vitro release of drug from the prepared transdermal films was carried out using vertical type of Franz diffusion cell with a receptor compartment capacity of $22 \mathrm{~mL}$. The jacketed diffusion cell with inlet and exit port for the circulation of water was used to maintain medium temperature at $32 \pm 0.5^{\circ} \mathrm{C}$. A film specimen of surface area $2.5 \mathrm{~cm} 2$ equivalent to $15 \mathrm{mg}$ of the drug was placed on 0.22 -lm cellulose acetate membrane which was previously equilibrated by soaking in phosphate buffer $\mathrm{pH} 7.4$ for $24 \mathrm{~h}$. The above medium was used to ensure the sink condition and stability of the drug. The membrane having film on it was immediately placed between the donor and receptor compartment and subsequently secured firmly by a stainless steel clip. The receptor compartment was stirred at $200 \mathrm{rpm}$ with a teflon-coated magnetic bead. Aliquots of $0.5 \mathrm{~mL}$ were withdrawn from the receptor compartment at specified time intervals $(0,2,4,8,12,16,20$, and $24 \mathrm{~h}$ ) and replaced with equal volumes of fresh buffer maintained at the same temperature. The samples were filtered and analyzed using a UV- Spectrophotometer (Shimadzu 1602, Japan) at $241 \mathrm{~nm}$.

\section{Stability of the transdermal films $[22,28]$}

Stability studies of the optimized formulation of prepared repaglinide transdermal film were carried out to determine the effect of formulation additives on the stability of the drug and also to determine the physical stability of the formulation. The optimized formulation was subjected to stability studies according to the ICH guidelines by storing at $25 \pm 2^{\circ} \mathrm{C} / 60 \pm 5 \% \mathrm{RH}$ and $30 \pm 2^{\circ} \mathrm{C} / 65 \pm 5 \% \mathrm{RH}$ for 12 months and $40 \pm 2^{\circ} \mathrm{C} / 75 \pm 5 \%$ RH for 6 months (Thermolab, Mumbai, India). The samples were analyzed and checked for changes in physical appearance and drug content at regular intervals.

\section{RESULTS AND DISCUSSION}

All formulations were prepared by solvent casting method using water and methanol as solvent system. The repaglinide-loaded films were slightly opaque, having smooth surface and elegant appearance. The physicochemical properties of the films are given in Table 2 . The thickness of the films found between 273 and $239 \mu \mathrm{m}$. As the concentration of KG was increased in the formulation, the thickness of the film decreased. This can be attributed to the high density of KG compared to HPMC K4M. The weight of the films varied from 71.8 to $77.4 \mathrm{mg}$, indicating that different proportion of KG has shown little or no significant impact on weight variation.

The main aim of the folding endurance study on transdermal films is to test the ability of the film to endure stress-based rupture during the application and use. The folding endurance values for the repaglinide films ranged from $240.9 \pm 8.7$ to $218.3 \pm 9.9$. This result clearly indicates that the repaglinide films are having optimum flexibility and are not brittle. However, it is clear that as the concentration of KG increased, the folding endurance decreased. This can be attributed to the complex structure and friable nature of KG. The higher values obtained demonstrated that films would maintain the integrity and shape with the natural folding of the skin when applied on it.
The drug content data were indicated good content uniformity with low standard deviation. This indicates that the films of repaglinide with HPMC K4M and KG can be prepared with a higher degree of reproducibility.

The mechanical properties such as tensile strength and \% elongation at break of all the repaglinide films were measured, and the data are shown in Table 2. A hard and tough polymeric film, generated from high values of both the studies, is always desired as it has qualities suited best as a drug delivery system for application on the skin. This implies that higher tensile strength values prevent abrasion of the film caused by contact with patient clothing, whereas higher \% elongation at break values allows the free movement of film on skin contact without breaking. The $\%$ elongation at break values ranged from $43 \pm 3.7$ to $31 \pm 4.1$ indicating good flexibility. It is clear that as the concentration of HPMC K4M increased, the value also increased. The tensile strength of the repaglinide films varied from $0.38 \pm 0.017$ to $0.53 \pm 0.016 \mathrm{~kg} / \mathrm{cm}^{2}$. The tensile strength values increased with increase in the concentration of KG in the film. This increase in value indicates that more force is required to deform the formulations having a high concentration of KG compared to HPMC K4M alone.

The moisture absorption is a tool to indicate how the film would behave during the initial stage of drug release. The lower moisture content in the formulations helps them to remain stable and become a completely dried and brittle film. Again, low moisture uptake protects the material from microbial contamination and bulkiness. The results of moisture content and moisture absorption studies are shown in Fig. 1a. The moisture content and \% moisture uptake in the repaglinide films ranged from 6.5 to 11.2 and $11.4 \%$ to $33.4 \%$, respectively, indicating that the values increased slightly due to increase of KG concentration in the films. This can be attributed to the hydrophilic nature of KG. The WVP values of the repaglinide films are shown in Fig. 1b. All the WVP values were found to be ranging between 632.17 and $573.74 \mathrm{~g} / \mathrm{m}^{2} /$ day. The average transepidermal water loss by diffusion through the skin is $300-400 \mathrm{~mL} /$ day which corresponds to $157.894-210.526 \mathrm{~g} / \mathrm{m}^{2} /$ day (normal body surface area is $1.9 \mathrm{~m}^{2}$ ). The obtained values indicate that the repaglinide films were not occlusive in nature and thereby do not disturb natural process of water loss from body surface.

The FTIR spectra of pure drug repaglinide and formulation F4 are shown in Fig. 2. The FTIR spectra of repaglinide and its formulation were found to be identical. The characteristic IR absorption peaks of repaglinide at $3320 \mathrm{~cm}^{-1}$ (N-H stretching), $2947 \mathrm{~cm}^{-1}$ (C-H stretching), $1728 \mathrm{~cm}^{-1}$ ( $\mathrm{C}=\mathrm{O}$ stretching), and $1460 \mathrm{~cm}^{-1}$ (C-H deformation) were obtained. The FTIR spectra of the pure drug, as well as drug incorporated formulation (F4), indicated that no chemical interaction occurred between the repaglinide and the polymers used. However, a slight change in absorption peaks position was noticed. This result clearly indicates that the drug and polymers used are compatible.

DSC thermograms of the pure drug and prepared formulation were recorded and shown in Fig. 3. From Fig. 3, it is clear that a sharp endothermic peak at $131^{\circ} \mathrm{C}$ was obtained for pure repaglinide. The melting point of repaglinide has not been seen in the prepared transdermal film, indicating that the drug has dispersed in micron level in the prepared films.

Table 2: Physicochemical properties of repaglinide transdermal films

\begin{tabular}{lllllll}
\hline $\begin{array}{l}\text { Formulation } \\
\text { code }\end{array}$ & Thickness $(\boldsymbol{\mu m})$ & $\begin{array}{l}\text { Weight } \\
\text { variation }(\mathbf{m g})\end{array}$ & $\begin{array}{l}\text { Folding } \\
\text { endurance }\end{array}$ & $\begin{array}{l}\text { Drug } \\
\text { content }(\mathbf{m g})\end{array}$ & $\begin{array}{l}\text { \% Elongation at } \\
\text { break }\end{array}$ & $\begin{array}{l}\text { Tensile strength } \\
\left.\mathbf{( k g}_{\mathbf{c m}} \mathbf{c m}^{2}\right)\end{array}$ \\
\hline F1 & $273 \pm 4.3$ & $71.82 \pm 2.16$ & $240.9 \pm 8.78$ & $15.3 \pm 0.65$ & $43 \pm 3.7$ & $0.38 \pm 0.017$ \\
F2 & $269 \pm 3.6$ & $72.29 \pm 1.92$ & $236.4 \pm 7.39$ & $15.9 \pm 0.46$ & $41 \pm 3.6$ & $0.39 \pm 0.014$ \\
F3 & $262 \pm 3.9$ & $73.25 \pm 1.57$ & $229.8 \pm 7.27$ & $14.5 \pm 0.61$ & $38 \pm 3.2$ & $0.42 \pm 0.018$ \\
F4 & $257 \pm 4.1$ & $74.04 \pm 1.24$ & $225.2 \pm 9.75$ & $15.4 \pm 0.53$ & $37 \pm 3.9$ & $0.46 \pm 0.012$ \\
F5 & $246 \pm 2.8$ & $76.92 \pm 1.64$ & $221.7 \pm 8.82$ & $15.2 \pm 0.52$ & $33 \pm 3.4$ & $0.49 \pm 0.015$ \\
F6 & $239 \pm 3.5$ & $77.41 \pm 1.53$ & $218.3 \pm 9.94$ & $14.6 \pm 0.68$ & $31 \pm 4.1$ & $0.53 \pm 0.016$ \\
\hline
\end{tabular}

Mean $\pm S D, n=6$ 


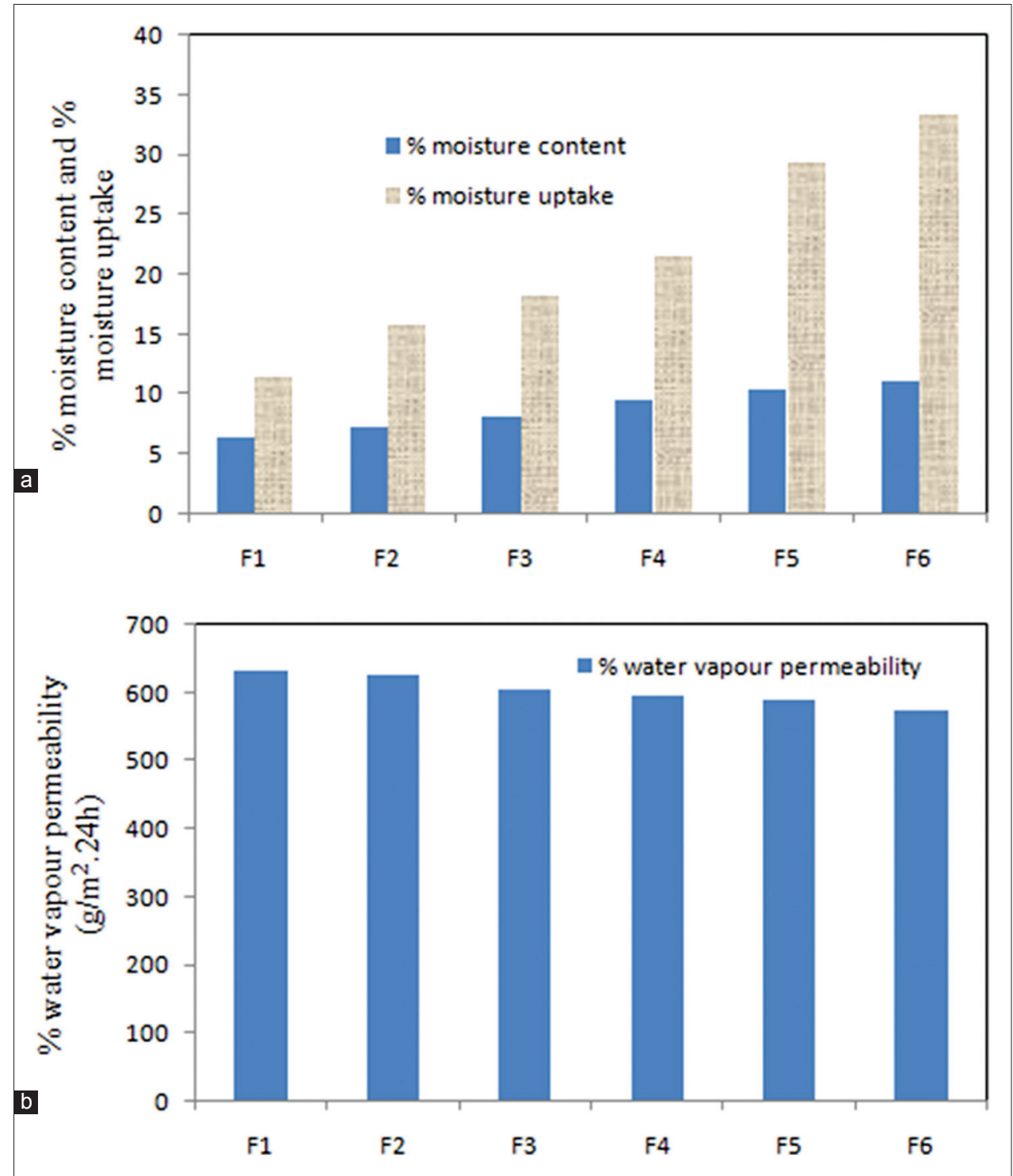

Fig. 1: (a) Percentage of moisture content and moisture absorption, and (b) percentage of water vapor permeation from prepared formulations

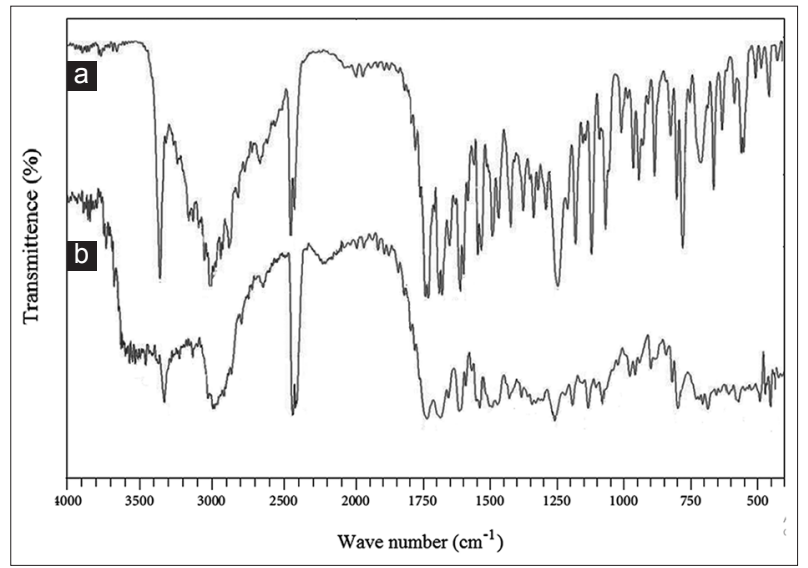

Fig. 2: Fourier-transform infrared spectra of repaglinide (a) and formulation F4 (b)

The drug release characteristics of the formulation were studied in in vitro conditions by using artificial semi-permeable membrane. The drug release profiles of the repaglinide films are shown graphically in Fig. 4. From Fig. 4, it is clear that as the concentration of KG in the formulation increased, the drug release from the transdermal film decreased. From Fig. 4, it is observed that the formulations F1-F3 have released $88.6,81.3$, and $74.1 \%$ of the drug within $12 \mathrm{~h}$ of the study period. Formulations F1 and F2 have released entire 100\% drug by $20 \mathrm{~h}$, whereas formulation F6 has released only $89.5 \%$ of drug in $20 \mathrm{~h}$ study period, indicating that they are not suitable for the present study. Formulations F3, F4, and F5 have released 99.1, 94.7, and 91.3\% of loaded drug indicating their suitability for $24 \mathrm{~h}$ drug release.

In vitro release study data of formulations $\mathrm{F} 3, \mathrm{~F} 4$, and $\mathrm{F} 5$ were fitted into various mathematical models to determine the best-fit model. The best-fit model with the highest regression coefficients $\left(R^{2}\right)$ for all the formulations is given in Table 3, and the best-fit model was found to be Higuchi model. To know the type of diffusion, all data were fitted to Korsmeyer-Peppas equation. The release exponent values $(\mathrm{n}=0.558-$ 0.623 ) demonstrated anomalous diffusion (non-Fickian model), i.e., the release mechanism followed the combination of diffusion and swelling. This is attributed to the presence of swelling polymers HPMC K4M and KG in the matrix. From Table 3, it was concluded that formulation F4 with $\mathrm{R}^{2}$ value of 0.9987 is the optimized formulation for $24 \mathrm{~h}$ study period.

Stability studies of the optimized repaglinide film were performed to ascertain if the drug undergoes any degradation during its shelf life. 


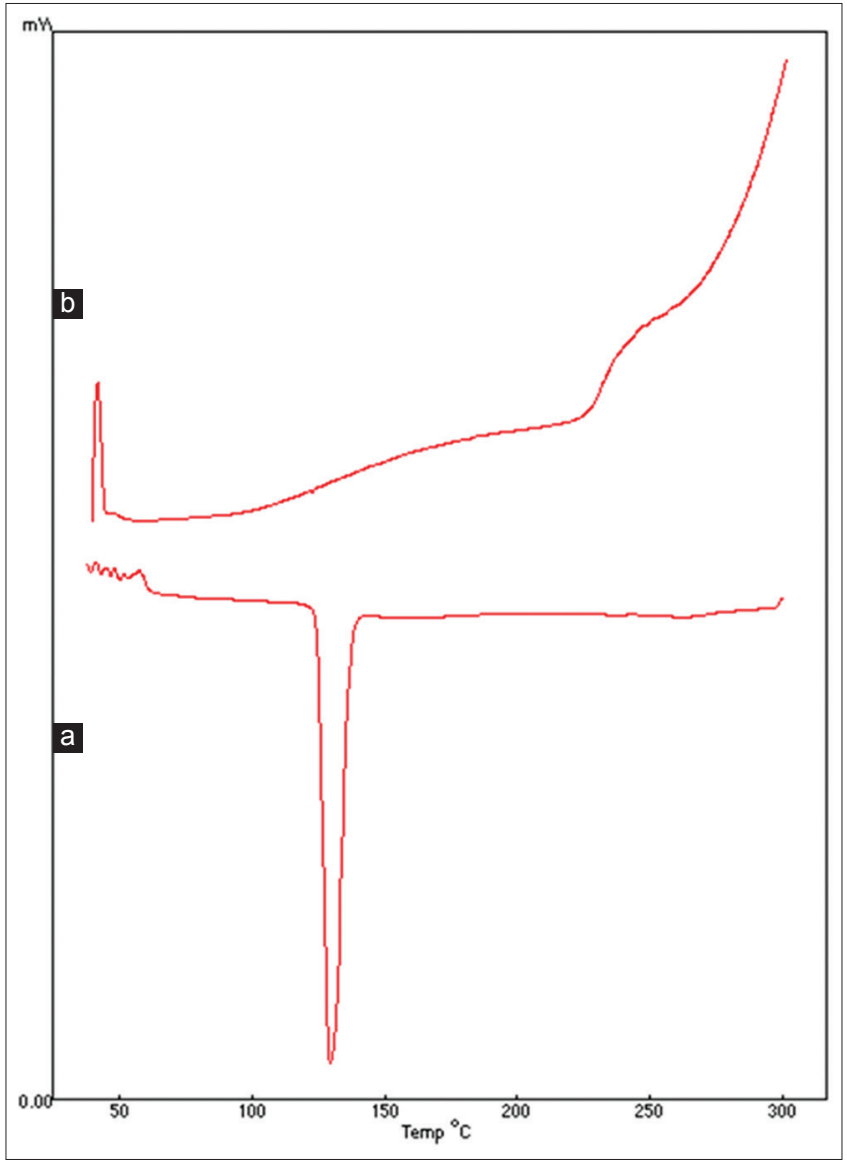

Fig. 3: Differential scanning calorimetry spectra of repaglinide (a) and formulation F4 (b)

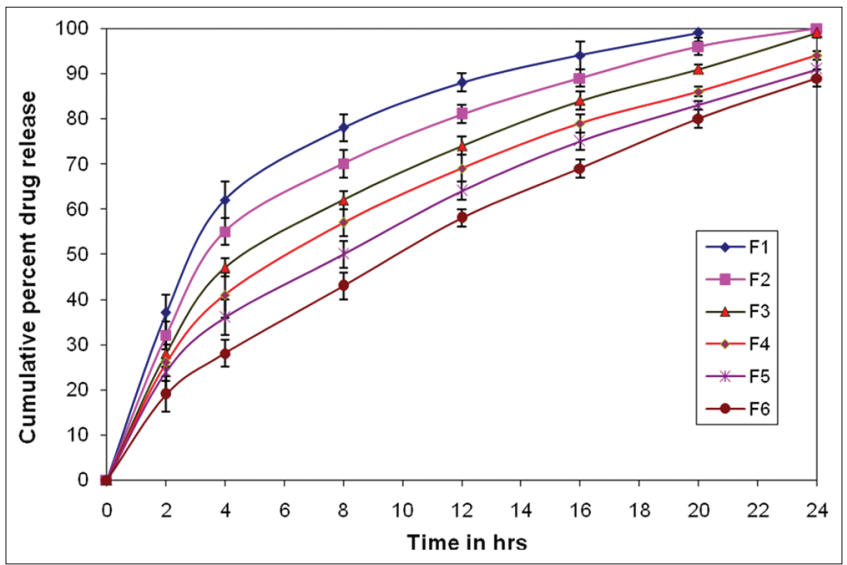

Fig. 4: In vitro drug release profiles from the prepared films

In the present study, the optimized formulation F4 was selected for stability studies. The obtained results of stability studies are given in Table 4. From Table 4, it can be concluded that the repaglinide is stable in the optimized formulation for the study period.

\section{CONCLUSION}

Repaglinide films were prepared by solvent casting method. The FTIR spectra of the pure drug, as well as drug incorporated formulation, indicated that no chemical interaction occurred between repaglinide and the polymers/excipients used. DSC thermograms of the pure drug and prepared formulation inferred that the drug has dispersed in micron level in the films. In vitro release study data of prepared formulations were fitted into various mathematical models and the best-fit model
Table 3: Model fitting data for the prepared formulations

\begin{tabular}{|c|c|c|c|}
\hline \multirow[t]{2}{*}{ Release model } & \multicolumn{3}{|c|}{ Formulation code } \\
\hline & F3 & F4 & F5 \\
\hline \multicolumn{4}{|l|}{ Zero order } \\
\hline $\mathrm{R}^{2}$ & 0.8467 & 0.8969 & 0.8292 \\
\hline \multicolumn{4}{|l|}{ First order } \\
\hline $\mathrm{R}^{2}$ & 0.9156 & 0.9342 & 0.9134 \\
\hline \multicolumn{4}{|l|}{ Hixson Crowell } \\
\hline $\mathrm{R}^{2}$ & 0.8421 & 0.8394 & 0.8396 \\
\hline \multicolumn{4}{|l|}{ Peppas } \\
\hline $\mathrm{R}^{2}$ & 0.8397 & 0.8746 & 0.8947 \\
\hline \multicolumn{4}{|l|}{ Higuchi } \\
\hline $\mathrm{R}^{2}$ & 0.9915 & 0.9987 & 0.9862 \\
\hline $\mathrm{n}$ & 0.623 & 0.558 & 0.617 \\
\hline Best-fit model & Higuchi & Higuchi & Higuchi \\
\hline
\end{tabular}

Table 4: Stability study data of optimized formulation F4

\begin{tabular}{|c|c|c|c|}
\hline \multirow[t]{2}{*}{ Stability condition } & \multirow{2}{*}{$\begin{array}{l}\text { Sampling } \\
\text { interval } \\
\text { (months) }\end{array}$} & \multicolumn{2}{|c|}{ Formulation F4 } \\
\hline & & $\begin{array}{l}\text { Physical } \\
\text { appearance }\end{array}$ & $\begin{array}{l}\% \text { Drug } \\
\text { content }\end{array}$ \\
\hline \multirow[t]{4}{*}{$25 \pm 2^{\circ} \mathrm{C} / 60 \pm 5 \% \mathrm{RH}$} & 0 & No change & $99.7 \pm 1.1$ \\
\hline & 3 & No change & $98.6 \pm 1.3$ \\
\hline & 6 & No change & $98.4 \pm 1.2$ \\
\hline & 12 & No change & $97.4 \pm 1.3$ \\
\hline \multirow{4}{*}{$30 \pm 2^{\circ} \mathrm{C} / 65 \pm 5 \% \mathrm{RH}$} & 0 & No change & $99.7 \pm 1.1$ \\
\hline & 3 & No change & $99.2 \pm 1.3$ \\
\hline & 6 & No change & $98.7 \pm 1.2$ \\
\hline & 12 & No change & $98.4 \pm 1.4$ \\
\hline \multirow[t]{3}{*}{$40 \pm 2^{\circ} \mathrm{C} / 75 \pm 5 \% \mathrm{RH}$} & 0 & No change & $99.7 \pm 1.1$ \\
\hline & 3 & No change & $98.6 \pm 1.2$ \\
\hline & 6 & No change & $97.1 \pm 1.3$ \\
\hline
\end{tabular}

was found to be Higuchi model. It was concluded that formulation F4 with $\mathrm{R}^{2}$ value of 0.9987 is the optimized formulation for $24 \mathrm{hr}$ study period. Stability studies of the drug formulations proved that the drug was stable in the optimized transdermal film formulation for the study period. Therefore, it can be concluded that the prepared film has the potential for transdermal drug delivery of repaglinide with improved permeation profile for longer period of time, thereby increasing the patient compliance.

\section{AUTHORS CONTRIBUTION}

All of the authors mentioned in the article have contributed equal efforts in this research work.

\section{CONFLICT OF INTEREST}

The authors would like to state that "we have no conflict of interest to declare."

\section{REFERENCES}

1. Cottrell IW, Kang KS, Kovaca P. Handbook of Water Soluble Gums and Resins. In: Davidson RL, editor. New York: McGraw Hill, Kingsport Press; 1980.

2. Arora S, Ali K, Ahuja A, Khar RK, Babota S. Floating drug delivery systems: A review. AAPS PharmSciTech 2005;6:372-90.

3. Streubel A, Siepmann J, Bodmeier R. Floating microparticles based on low density foam powder. Int J Pharm 2002;241:279-92.

4. Ahad A, Aqil M, Kohli K, Sultana Y, Mujeeb M, Ali A. Transdermal drug delivery: The inherent challenges and technological advancements. Asian J Pharm Sci 2010;5:276-89.

5. Ahad A, Al-Jenoobi FI, Al-Mohizea AM, Akhtar N, Raish M, Aqil M, et al. Systemic delivery of $\beta$-blockers via transdermal route for hypertension. Saudi Pharm J 2015;23:587-602.

6. Karki S, Kim H, Seon-Jeong N, Shin D, Jo K, Lee J. Thin films as an emerging platform for drug delivery. Asian J Pharm Sci 2016;11:559- 74.

7. Sharma D, Kaur D, Verma S, Garg S. Fast dissolving oral films 
technology: A recent trend for an innovative oral drug delivery system. Int J Drug Deliv 2015;7:60-75

8. Putri KS. Pregelatinized cassava starch phthalate as film-forming excipient for transdermal film of ketoprofen. Asian J Pharm Clin Res 2013;6:62-6.

9. Hamdan L, Husian J. Formulation and evaluation in vitro a matrix type of ketotifen fumarate transdermal patches for allergic diseases. Asian J Pharm Clin Res 2017;10:327-33.

10. Castro PM, Fonte P, Sousa F, Raquel MA, Bruno S, Manuel EP. Oral films as breakthrough tools for oral delivery of proteins/ peptides. J Control Release 2015;211:63-73.

11. Achouri D, Alhanout K, Piccerelle P, Andrieu V. Recent advances in ocular drug delivery. Drug Dev Ind Pharm 2013;39:1599-617.

12. Vinod VT, Sashidhar R. Surface morphology, chemical and structural assignment of gum kondagogu (Cochlospermum gossypium D.C): An exudates tree gum of India. Ind J Nat Prod Res 2010;1:181-92.

13. Janaki B, Sashidhar RB. Physico-chemical analysis of gum kondagogu (Cochlospermum gossypium): A potential food additive. Carbohydr Polym 2009;76:464-71.

14. Vinod VT, Sashidhar RB, Sarma VU, Saradhi UV, Compositional analysis and rheological properties of gum kondagogu (Cochlospermum gossypium): A tree gum from India. J Agric Food Chem 2008;56:2199- 207.

15. Vinod VT, Sashidhar RB, Sreedhar B. Biosorption of nickel and total chromium from aqueous solution by gum kondagogu (Cochlospermum gossypium): A carbohydrate biopolymer. J Hazard Mater 2010;178:851- 60

16. Saravanan P, Vinod VT, Sreedhar B, Sashidhar RB. Gum kondagogu modified magnetic nano-adsorbent: An efficient protocol for removal of various toxic metal ions. Mater Sci Eng C 2012;32:581-6.

17. Ravi V, Kumar TM. Investigation of kondagogu gum as a pharmaceutical excipient: A case study in developing floating matrix tablet. Int J PharmTech Res 2013;5:70-8.

18. Kumar A, Ahuja M. Carboxymethyl gum kondagogu-chitosan polyelectrolyte complex nanoparticles: Preparation and characterization.
Int J Biolog Macromol 2013;62:80-4

19. Ghosal K, Rajan R, Nanda A. Effects of chemical enhancers on the release of glipizide through matrix patch. Int $\mathrm{J}$ ChemTech Res 2009;1:1128-30.

20. Vijayan V, Reddy KR, Sakthivel S, Swetha C. Optimization and charaterization of repaglinide biodegradable polymeric nanoparticle loaded transdermal patchs: In vitro and in vivo studies. Colloids Surf B Biointerfaces 2013;111:150-5.

21. Khan KA. Drug utilization study of antihyperglycemic agents in outpatients at OPD clinics in south Indian metropolitan city. Int J Pharm Pharm Sci 2016;8:58-61

22. Ammar HO, El-feky GS, Ali AM, Dawood RA. Enhancement of oral bioavailability of repaglinide by self-nanoemulsifying drug delivery system. Int J Pharm Pharm Sci 2014;6:603-6.

23. Kumar TM, Umesh HM, Shivakumar HG, Ravi V, Siddaramaiah. Feasibility of polyvinyl alcohol as a transdermal drug delivery system for terbutaline sulphate. J Mac Sci Part A 2007;44:583-9.

24. Shinde AJ, Garala KC, More HN. Development and characterization of transdermal therapeutics system of tramadol hydrochloride. Asian J Pharm 2008;12:265-9.

25. Tirunagari M, Jangala VR, Khagga M, Gannu R. Transdermal therapeutic system of isradipine: Effect of hydrophilic and hydrophobic matrix on in vitro and ex vivo characteristics. Arch Pharm Res 2010;33:1025-33.

26. Dhole SM, Khedekar PB, Amnerkar ND. Comparison of UV spectrophotometry and high performance liquid chromatography methods for the determination of repaglinide in tablets. Pharm Methods 2012;3:68-72.

27. Patel DP, Setty CM, Mistry GN, Patel SL, Patel TJ, Mistry PC, et al. Development and evaluation of ethyl cellulose-based transdermal films of furosemide for improved in vitro skin permeation. AAPS PharmSciTech 2009; 10:437-42

28. Padula C, Colombo G, Nicoli S, Catellani PL, Massimo G, Santi P, et al. Bioadhesive film for the transdermal delivery of lidocaine: In vitro and in vivo behavior. J Control Release 2003;88:277-85. 